\title{
2008/58
}

Should we subsidize longevity?

Marie-Louise Leroux, Pierre Pestieau and Grégory Ponthière 
CORE

Voie du Roman Pays 34

B-1348 Louvain-la-Neuve, Belgium.

Tel (32 10) 474304

Fax (32 10) 474301

E-mail: corestat-library@uclouvain.be http://www.uclouvain.be/en-44508.html 


\title{
CORE DISCUSSION PAPER
}

$2008 / 58$

\section{Should we subsidize longevity?}

\author{
Marie-Louise LEROUX ${ }^{1}$, Pierre PESTIEAU ${ }^{2}$ \\ and Grégory PONTHIERE ${ }^{3}$
}

October 2008

\begin{abstract}
This paper studies the design of the optimal non linear taxation in an economy where longevity varies across agents, and depends on three factors: longevity genes, health investment and farsightedness. Provided earnings, farsightedness and genes are correlated, governmental intervention can be justified on two grounds: correction for a lack of farsightedness and redistribution across both earnings and genetic dimensions. Whether longevity-enhancing spending should be subsidized or taxed is shown to depend on the combined effects of myopia, self-selection and free-riding on the annuity returns. Our policy conclusions depend also on how productivity and genes are correlated, on the complementarity of genes and efforts in the survival function, and on how the government weights the welfare of heterogeneous agents. All in all, it might be desirable to tax longevityenhancing spending.
\end{abstract}

Keywords: optimal taxation, longevity, genetic background, heterogeneity, myopia.

JEL Classification: H21, I10

${ }^{1}$ CORE, Université catholique de Louvain, Belgium. E-mail: marie-louise.leroux@uclouvain.be.

${ }^{2}$ University of Liege, CREPP, CORE, PSE and CEPR.

${ }^{3}$ PSE and Ecole Normale Supérieure, Paris, France. E-mail: Gregory.ponthiere@ens.fr

The authors thank Erik Schokkaert for his helpful comments on this paper.

This paper presents research results of the Belgian Program on Interuniversity Poles of Attraction initiated by the Belgian State, Prime Minister's Office, Science Policy Programming. The scientific responsibility is assumed by the authors. 



\section{Introduction}

Should the government subsidize longevity?

At first glance, that question sounds more provocative than really relevant, as this seems to question something unquestionable. Clearly, there can be no doubt that the large rise in longevity that we are witnessing is a good thing. ${ }^{1}$ Moreover, it seems also obvious that, keeping everything else constant, "more life is generally better than less life". Hence, it is tempting to conclude that the government should intervene to promote longer lives.

However, by no way do those considerations necessarily imply that the government has to intervene and influence individual choices pertaining to longevity. The reason why this is not the case is related to the - often implicit - ceteris paribus postulate underlying the "more is always better" belief.

The goal of this paper is to re-examine the determinants of the optimal subsidization of health spending in an economy where longevity is endogenous. $^{2}$ In particular, we shall argue that there might be some reasons why the government should intervene negatively, and tax longevity, contrary to the common sense (recommending the subsidization of longevity). Each of those reasons involves a particular violation of the ceteris paribus postulate.

The first reason is linked to the annuitization of savings when life duration is uncertain. As shown by Becker and Philipson (1998), individuals do not take into account, in their longevity-related choices, the negative effect that these choices can have on the cost of annuities, and, thus, on the return of their savings. As a consequence, agents may tend to invest too much in their health in comparison with what would maximize lifetime welfare.

The second reason is linked to redistribution. If richer individuals tend to invest more in longevity-enhancing activities, it can be socially optimal to tax them in a second-best setting wherein the social planner observes neither productivity nor longevity genes. In other words, the taxation of longevityenhancing activities can serve as an indirect way to achieve social welfare maximization in the context of asymmetric information.

Whereas those two reasons support the taxation of longevity-enhancing health spending, the study of the optimal taxation under endogenous longevity requires also to take into account other dimensions of the problem, which can make individual choices suboptimal. In particular, there is another argument that leads to an opposite policy, namely to subsidize longevity. If agents, because of their ignorance or myopia, do not perceive the deferred effect that

\footnotetext{
${ }^{1}$ That intuition is confirmed by various preferences-based indicators of standards of living taking longevity into account [see Becker et al (2005) and Murphy and Topel (2006)].

${ }^{2}$ As such, this is complementary to the studies by Bommier et al $(2007 \mathrm{a}, \mathrm{b})$ focusing on economies where longevity is exogenous.
} 
their savings and health care choices may have on their future consumption and their longevity, such an imperfection of behavior invites some governmental correction against individual underinvestment in health.

This paper proposes to re-examine the design of optimal taxation in an economy where longevity is endogenous, and where the three considerations discussed above interact. For that purpose, we develop a two-period model where agents can influence their probability of survival to the second period by means of some first-period health spending. Moreover, in order to do justice to the heterogeneity of real populations, agents are here assumed to differ in three characteristics: their productivity, their genetic background and their degree of myopia.

At this early stage of our study, it might be worth highlighting four limitations of this paper. First, we shall concentrate here on longevity-enhancing efforts of monetary nature, and leave aside all other kinds of efforts promoting longevity, such as temporal efforts (e.g. jogging) and physical efforts (e.g. abstinence). Second, we shall focus on health spending that only concerns the quantity of life, and not its quality. In other words, health spending shall be here longevity-enhancing spending, which shall not affect lifetime welfare through other means than the mere lengthening of life. Third, this study will rely on a static framework, and will leave aside various dynamic arguments supporting the subsidization of longevity. ${ }^{3}$ Fourth, this normative discussion will be - almost exclusively - carried out under the postulate of classical utilitarianism, which exhibits, in our context, two weaknesses. On the one hand, the reliance of utilitarianism on consequentialism can hardly do justice to intuitions about responsibility (as only outcomes matter); on the other hand, the classical form of utilitarianism equalizes to zero the critical utility level beyond which existence is desirable, which is also debatable. ${ }^{4}$ Thus classical utilitarianism can only be justified on the grounds of analytical convenience.

Finally, although one may be skeptical and/or shocked in front of the question raised by this paper, it should be stressed that the absence of theoretical discussions on an issue is generally more damageable than such discussions, as the default option - i.e. the current practice - is often non-optimal. Having stressed this, it is clear that this study does not have the pretension to bring an exhaustive answer to the question of governments'attitudes towards longevity, but is only a first step to be complemented by others. ${ }^{5}$

\footnotetext{
${ }^{3}$ For dynamic studies of optimal taxation on health spending, see Zhang et al (2006), Jouvet et al (2007) and Pestieau et al (2008).

${ }^{4}$ See Broome (2004) on this.

${ }^{5}$ See Leroux et al (2008) for a study of the optimal linear taxation under endogenous longevity when agents differ in productivity and genes. Other studies of optimal taxation under endogenous longevity include Leroux (2008) and Leroux and Ponthiere (2008).
} 
The rest of this paper is organized as follows. Section 2 presents the model and describes the laissez-faire equilibrium. Section 3 characterizes the social optimum, and studies its decentralization under full information. The second-best problem is examined in Section 4, under the postulate of complementarity between genetic endowment and health spending in the production of longevity, and for various assumptions on the correlation between individual productivity and genetic background. Section 5 discusses the sensitivity of our policy conclusions to some crucial assumptions. Section 6 concludes.

\section{The model}

\subsection{Basic assumptions}

We consider a two-period model in which individuals live the first period with certainty, and the second one with a probability $\pi$. The survival probability $\pi$ of an agent of type $i$ depends on (first-period) health expenditures $e_{i}$, and on a genetic (exogenous) characteristic $\varepsilon_{i}$ :

$$
\pi_{i}=\pi\left(e_{i}, \varepsilon_{i}\right)
$$

where first and second derivatives are such that $\pi_{e}>0, \pi_{e e}<0, \pi_{\varepsilon}>0$, and $\pi_{\varepsilon \varepsilon}<0$. We also assume that genetics and health expenditures are complements, so that the impact of health expenditures is higher when the individual has better genes (i.e. $\left.\pi_{e \varepsilon}>0\right){ }^{6}$ The function $\pi\left(e_{i}, \varepsilon_{i}\right)$ is a survival probability, but it gives us also the actual proportion of survivors of type $i$.

Throughout this paper, we shall assume that agents do not necessarily have a correct perception of their actual survival probability. They make their saving and health spending decisions on the basis of a perceived survival function $\hat{\pi}_{i}$ defined as:

$$
\hat{\pi}_{i}=\alpha_{i} \pi\left(e_{i}, \varepsilon_{i}\right)
$$

where the parameter $\alpha_{i} \in[0,1]$ (or rather $1-\alpha_{i}$ ) stands for the individual's degree of ignorance or myopia. ${ }^{7}$ People with a low $\alpha_{i}$ hardly realize that they can lengthen their life by investing $e_{i}$ even though it is true, while people with $\alpha_{i}=1$ fully internalize the impact of their effort on their longevity.

\footnotetext{
${ }^{6}$ We believe that this assumption is more plausible than that of substitutability. The robustness of our results to this assumption is examined in Section 5.2 below.

${ }^{7}$ Note that this specification of agents' myopia is here made for conveniency. Assuming $\alpha_{i}<1$ amounts to consider that agents tend systematically to underestimate their probability of survival (i.e. pessimism). Naturally, other, more general assumptions could be made on agents' myopia (allowing, for instance, optimism), but these would induce additional subcases for our analysis without bringing new insights.
} 
Individuals differ in three dimensions: their genetic characteristics $\varepsilon_{i}$, their degree of myopia $\alpha_{i}$, and their labor productivity $w_{i}$. Whereas both $\varepsilon_{i}$ and $w_{i}$ are assumed to be non observable, $\alpha_{i}$ is common knowledge.

Lifetime welfare is assumed to be additive over time, and temporal welfare depends on consumption during the period. Setting the discount and interest rates equal to zero and assuming that the utility of being dead is normalized to zero, the expected lifetime utility of an individual of type $i$ is given by:

$$
U\left(c_{i}, d_{i}, l_{i}\right)=u\left(c_{i}\right)+\alpha_{i} \pi\left(e_{i}, \varepsilon_{i}\right) u\left(d_{i}\right)-v\left(l_{i}\right)
$$

where $c_{i}$ and $d_{i}$ denote the consumption in first and second period respectively, $l_{i}$ is the labor supply in the first period. Per period utility of consumption, $u(\cdot)$ is such that $u^{\prime}(\cdot)>0$ and $u^{\prime \prime}()<$.0 . The disutility of labor is increasing and strictly convex: $v^{\prime}(\cdot)>0$ and $v^{\prime \prime}(\cdot)>0$.

\subsection{The laissez-faire}

We assume that individuals invest all their savings on a perfect annuity market. An individual of type $i$ chooses his savings $s_{i}$ and his health expenditure $e_{i}$ by solving the following problem:

$$
\begin{aligned}
& \max u\left(c_{i}\right)+\alpha_{i} \pi\left(e_{i}, \varepsilon_{i}\right) u\left(d_{i}\right)-v\left(l_{i}\right) \\
& \text { s.t. }\left\{\begin{array}{c}
c_{i}=w_{i} l_{i}-s_{i}-e_{i} \\
d_{i}=s_{i} R_{i}
\end{array}\right.
\end{aligned}
$$

where $R_{i}$ is the return on saving, which is taken as given. FOCs are

$$
\begin{aligned}
u^{\prime}\left(c_{i}\right) w_{i} & =v^{\prime}\left(l_{i}\right) \\
u^{\prime}\left(c_{i}\right) & =u^{\prime}\left(d_{i}\right) R_{i} \alpha_{i} \pi\left(e_{i}, \varepsilon_{i}\right) \\
u^{\prime}\left(c_{i}\right) & =\alpha_{i} \pi_{e}\left(e_{i}, \varepsilon_{i}\right) u\left(d_{i}\right)
\end{aligned}
$$

We assume that the market for annuities is actuarially fair, so that:

$$
R_{i}=\frac{1}{\pi\left(e_{i}, \varepsilon_{i}\right)}
$$

with a zero rate of interest. Note that the return of the annuity depends on the actual survival of individual. Equation (4) is standard: the marginal rate of substitution between labor and consumption is equal to the wage rate. Equation (5) defines the optimal level of savings. If the individual is perfectly rational $\left(\alpha_{i}=1\right)$, consumption is smoothed $\left(c_{i}=d_{i}\right)$; on the contrary, for any $\alpha_{i}<1$, first period consumption is higher than second period consumption. 
Equation (6) yields the level of health investment. The LHS of this equation is the utility cost associated to foregone consumption while the RHS is the utility gain from a larger health spending, which depends on the utility of the second period consumption, on the effect of health spending on longevity, but, also, on the degree of rationality of the agent. Note that the level of health spending decreases with the degree of myopia. Moreover, in the laissez-faire, the individual takes the return of the annuity as given, and does not internalize the impact of his health spending on the annuity return. This behavioral imperfection was first highlighted by Becker and Philipson (1998): when choosing their longevity effort, individuals face a free-rider problem, and choose their longevity effort without taking into account that it affects the annuity price. ${ }^{8}$ Thus, as it will appear, the laissez-faire level of health spending is, in the absence of myopia, higher than the optimal one.

\section{Paternalistic optimum}

In this study, the social planner is assumed to be utilitarian and paternalistic.

By a 'utilitarian' planner, we mean that the planner pursues the standard Benthamite goal of the maximization of the sum of individual utilities. That ethical framework suffers from several weaknesses in our context. In particular, its reliance on consequentialism makes it hard to account for issues of responsibility (as only outcomes matter from a consequentialist point of view). Moreover, as this is well-known in the population ethics literature, utilitarianism in its classical form exhibits limitations in the context of varying longevity: this regards any life with a positive (even extremely low) utility level as desirable. ${ }^{9}$ Thus, classical utilitarianism should only be regarded as an - analytically attractive - starting point for the issue at stake.

By 'paternalistic' planner, we mean that the planner uses, in his maximization program, the true survival probability, and not the one perceived by individuals. The social planner's motivation is standard in self-control problems: the planner knows that individuals will be grateful to him to have forced them to behave according to their true survival probabilities.

\footnotetext{
${ }^{8}$ The intuition goes as follows: each person, by considering himself as one among a multitude of agents, believes that he cannot influence the return on savings through his own survival, even though it happens to do so.

${ }^{9}$ On this, see Broome (2004).
} 


\subsection{First-best solution}

In the first-best setting, the central planner observes the types of individuals, namely their productivity and genes, and ignores any myopia. Its problem is thus to maximize.

$$
\sum n_{i}\left[u\left(c_{i}\right)+\pi\left(e_{i}, \varepsilon_{i}\right) u\left(d_{i}\right)-v\left(\frac{y_{i}}{w_{i}}\right)\right]
$$

subject to the resource constraint of the economy

$$
\sum n_{i}\left(c_{i}+e_{i}+\pi\left(e_{i}, \varepsilon_{i}\right) d_{i}-y_{i}\right)=0
$$

where $n_{i}$ is the proportion of individuals of type $i$, namely with characteristics $\varepsilon_{i}, w_{i}$ and $\alpha_{i}$. For simplicity, we also replace $w_{i} l_{i}$ by $y_{i}$, the gross income earned by an individual with productivity $w_{i}$. The FOCs of this problem can be rearranged as

$$
\begin{aligned}
v^{\prime}\left(l_{i}\right) & =\mu w_{i} \\
u^{\prime}\left(c_{i}\right)=u^{\prime}\left(d_{i}\right) & =\mu \\
\pi_{e}\left(e_{i}, \varepsilon_{i}\right) u\left(d_{i}\right) & =\mu\left[1+\pi_{e}\left(e_{i}, \varepsilon_{i}\right) d_{i}\right]
\end{aligned}
$$

where $\mu$ is the Lagrange multiplier associated with the resource constraint. First, from equation (8), individuals with higher productivity should supply more labor $l_{i}$ than individuals with lower productivity. Second, equation (9) shows that consumption should be equalized for all types periods, $c_{i}=d_{i}=$ $\bar{c} \forall i$. This is a direct implication of both utilitarianism and of additivity across periods in individual lifetime utility.

Equation (10) gives the optimal level of health expenditure. Rearranging it, we obtain

$$
\pi_{e}\left(e_{i}, \varepsilon_{i}\right)=\frac{F}{1-\bar{c} F}
$$

where $F \equiv u^{\prime}(\bar{c}) / u(\bar{c})$ is called "fear of ruin" and is an alternative measure of risk aversion. ${ }^{10}$

Comparing (11) with its laissez-faire counterpart (6), which can be rearranged as $\pi_{e}\left(e_{i}, \varepsilon_{i}\right)=F / \alpha_{i}$, this condition differs on two grounds. With $\alpha_{i}=1$, the first-best FOC differs from the laissez-faire FOC (6) by a term $-\bar{c} F$ in the denominator, which reflects the impact of health spending on the budget set. This is the "Becker-Philipson" effect (hereafter, referred as the BP effect). The first-best level of health spending is thus lower than the laissez-faire one. This first-best expression also differs from the laissez-faire

\footnotetext{
${ }^{10}$ On the fear of ruin, see Eeckhoudt and Pestieau (2008).
} 
by $\alpha_{i}$. In the first-best, the impact of effort on survival is fully internalized: this contributes to make the first-best effort exceed its laissez-faire level. Since both effects (Becker-Philipson and myopia) go into opposite directions, whether the first-best level of effort is superior or inferior to the laissez-faire one is not clear.

Note that in the first-best, health spending are differentiated according to genetic endowment $\varepsilon_{i}$, but not with respect to the degree of rationality of individuals $\alpha_{i}$. Assuming, in a paternalistic way, that $\alpha_{i}=1 \forall i$ leads the social planner to redistribute only according to individual genetic endowment and labor productivity, but not according to their degree of myopia. ${ }^{11}$

According to equation (11), the differential value of $e_{i}$ only depends on $\varepsilon_{i}$. It is immediate to see that $\varepsilon_{i}>\varepsilon_{j}$ implies $e_{i}>e_{j}$ if $\pi_{\varepsilon e}>0$, that is, if both arguments are complements. In this paper, for the sake of simplicity, we focus on the cases where type- 2 agents are tempted to mimic type- 1 agents. This possibility appears if

$$
u\left(c_{2}\right)+\alpha_{2} \pi\left(\varepsilon_{2}, e_{2}\right) u\left(c_{2}\right)-v\left(l_{2}\right) \leq u\left(c_{1}\right)+\alpha_{2} \pi\left(\varepsilon_{2}, e_{1}\right) u\left(c_{1}\right)-v\left(\frac{y_{1}}{w_{2}}\right)
$$

where the values $c_{i}, d_{i}, y_{i}, l_{i}$ and $e_{i}$ are those of the first-best, and parameters $\varepsilon_{2}$ and $w_{2}$ are not common knowledge. For such a mimicking to be possible, it is essential that type- 2 agents benefit from characteristics $w_{2}$ and $\varepsilon_{2}$ that, in combination, imply a social redistribution that they would prefer to avoid, which is possible if those characteristics are not observable. The first-best optimum implies transfers from individuals with the higher productivity towards the ones with the lower productivity, but, also, transfers from individuals with the worse genetic background towards the ones with the better genetic background. This is the consequence of our social welfare function. We come back to that issue below.

\subsection{Decentralization}

Let us now consider how the above paternalistic optimum can be decentralized. In the following, we assume that the instruments available to the social planner are: individualized linear taxes on labor $\tau_{i}$, on health $\theta_{i}$, and on savings $\sigma_{i}$, as well as individualized lump sum transfers $T_{i}$. We also assume that the annuity market is actuarially fair, so that $R_{i}=1 / \pi\left(e_{i}, \varepsilon_{i}\right)$ prevails at the equilibrium. The individual's problem is thus to maximize:

$$
u\left(w_{i} l_{i}\left(1-\tau_{i}\right)-s_{i}\left(1+\sigma_{i}\right)-e_{i}\left(1+\theta_{i}\right)+T_{i}\right)-v\left(l_{i}\right)+\alpha_{i} \pi\left(e_{i}, \varepsilon_{i}\right) u\left(R_{i} s_{i}\right)
$$

\footnotetext{
${ }^{11}$ One may interpret this in the following way: agents are not held responsible for their myopia, because the social planner corrects their decisions.
} 
Solving this problem, we obtain the following FOCs,

$$
\begin{aligned}
\frac{v^{\prime}\left(l_{i}\right)}{u^{\prime}\left(c_{i}\right)} & =w_{i}\left(1-\tau_{i}\right) \\
\frac{\alpha_{i} u^{\prime}\left(d_{i}\right)}{u^{\prime}\left(c_{i}\right)} & =1+\sigma_{i} \\
\frac{\alpha_{i} \pi_{e}\left(e_{i}, \varepsilon_{i}\right) u\left(d_{i}\right)}{u^{\prime}\left(c_{i}\right)} & =1+\theta_{i}
\end{aligned}
$$

We then compare these FOCs with the FOCs (8)-(10) of the first-best to see how the optimum can be decentralized with our tax instruments. We easily obtain the following values for the taxes:

$$
\begin{aligned}
\tau_{i} & =0 \\
\sigma_{i} & =\alpha_{i}-1 \leqslant 0 \\
\theta_{i} & =\left[1+\pi_{e}\left(e_{i}, \varepsilon_{i}\right) d_{i}\right] \alpha_{i}-1
\end{aligned}
$$

The social optimum can be reached with a zero tax on labor. It is optimal to subsidize savings for any agent of type $i$ with $\alpha_{i}<1$. This is simply to correct for individual myopia: since myopic agents do not save enough in the laissez-faire, it is optimal to subsidize their savings so as to encourage them to save more. In the absence of myopia (i.e. $\alpha_{i}=1$ ), the tax $\sigma_{i}$ is zero.

On the contrary, the sign of $\theta_{i}$ is ambiguous, as it depends on two countervailing effects. To see this, let us first assume that individuals are fully rational (i.e. $\alpha_{i}=1$ ). In this case, health spending is taxed and $\theta_{i}=\pi_{e}\left(e_{i}, \varepsilon_{i}\right) d_{i}$. This is to correct for the overspending in health noted by Becker-Philipson (1998): in order to make agents choose the optimal level of health spending, one has to tax health expenditures. Let us now assume that there is no BP effect and that the individual perfectly anticipates the effect of his health spending on the annuity return. In this case, $\theta_{i}=\alpha_{i}-1$ and it would be optimal to subsidize health expenditures so as to counterbalance the effect of myopia, which makes individuals invest too little in their health. Thus, depending on the magnitude of these two effects, $\theta_{i}$ is positive or negative.

Table 1 summarizes the impact of both MO (myopia) and BP effects on the level of taxes on savings, health expenditures and labor:

Table 1: First-best taxation

\begin{tabular}{|c||c|c|c|}
\hline Taxes & BP & MO & Total effect \\
\hline \hline$\sigma_{i}$ & 0 & - & - \\
\hline$\theta_{i}$ & + & - & $?$ \\
\hline$\tau_{i}$ & 0 & 0 & 0 \\
\hline
\end{tabular}


Note finally that since the subsidy on savings depends on $\alpha_{i}$, agents with different degrees of myopia will face different subsidies; yet, this tax does not depend on the other individual characteristics $\left(w_{i}, \varepsilon_{i}\right)$. In contrast, the level of taxes/subsidies on health expenditures will depend not only on the agent's degree of myopia, but, also, on his genetic background through the survival probability $\pi\left(e_{i}, \varepsilon_{i}\right)$. For instance, an individual with a very good genetic background and a low degree of myopia may face a tax on health spending, while an individual with a low genetic background but a high myopia might be subsidized in the first-best.

To achieve the FB solution, we need the above taxes or subsidies, but, also, appropriate lump sum taxes. Under $\alpha_{i}=1$, the tax structure will be such that $c_{i}=d_{i}=\bar{c}$ and $\pi_{e}\left(e_{i}, \varepsilon_{i}\right)$ is constant. With equal $\varepsilon_{i}$, if $w_{2}>w_{1}$, the lump sum tax would redistribute from type- 2 agents to type- 1 agents, to allow both of them to make the same choices. Unequal $\varepsilon_{i}$ along with complementarity of $e_{i}$ and $\varepsilon_{i}$ imply that, if $\varepsilon_{2}>\varepsilon_{1}$, the redistribution will go from type- 1 agents to type- 2 agents. Which one of the two redistributions dominates is uncertain. To the extent that we want to focus on the case where type- 2 agents mimic type- 1 agents, we shall, in the rest of this paper, adopt the characteristics' values that give us this outcome.

\section{Second-best non linear taxation}

\subsection{Incentive constraints and the planner's problem}

We now turn to the second-best case wherein the social planner cannot observe individuals' types $\left(w_{i}, \varepsilon_{i}\right)$. By assumption, the degree of myopia is still observable, and, for simplicity, $\alpha_{1}=\alpha_{2}<1$. Let us consider two types of agents with characteristics $\left(w_{1}, \varepsilon_{1}\right)$ and $\left(w_{2}, \varepsilon_{2}\right)$. Under asymmetric information, whether type-1 agents mimic type- 2 agents or the reverse depends on whether $w_{1} \gtrless w_{2}$ and $\varepsilon_{1} \lessgtr \varepsilon_{2}$. Four cases can be distinguished:

- Case A: $w_{2} \geqslant w_{1}$ and $\varepsilon_{1} \geq \varepsilon_{2}$

- Case B: $w_{2} \geqslant w_{1}$ and $\varepsilon_{1}<\varepsilon_{2}$

- Case C: $w_{2}<w_{1}$ and $\varepsilon_{1}>\varepsilon_{2}$

- Case D: $w_{2}<w_{1}$ and $\varepsilon_{1} \leq \varepsilon_{2}$

Substituting the first-best allocation into the incentive constraint, it is straightforward to see that under asymmetric information, type- 2 agents will 
always mimic type- 1 agents in case A. ${ }^{12}$ Such a mimicking will also occur in case $\mathrm{B}$ if the gap between $\varepsilon_{1}$ and $\varepsilon_{2}$ is small relative to the productivity gap, and in case $\mathrm{C}$ if the genetic gap is high relative to the productivity gap. In case D, type- 2 agents have never interest in mimicking type- 1 agents. We will thus exclude case D, and suppose that the most realistic case is B, where genes and productivities are positively correlated.

Hence, only considering the cases where type- 2 agents mimic type- 1 agents, the social planner's problem can be expressed by the following Lagrangian:

$$
\begin{aligned}
£=\quad & \sum n_{i}\left[u\left(c_{i}\right)+\pi\left(e_{i}, \varepsilon_{i}\right) u\left(d_{i}\right)-v\left(\frac{y_{i}}{w_{i}}\right)-\mu\left(c_{i}+e_{i}+\pi\left(e_{i}, \varepsilon_{i}\right) d_{i}-y_{i}\right)\right] \\
+ & \lambda\left[u\left(c_{2}\right)+\alpha_{2} \pi\left(e_{2}, \varepsilon_{2}\right) u\left(d_{2}\right)-v\left(\frac{y_{2}}{w_{2}}\right)\right. \\
& \left.-u\left(c_{1}\right)-\alpha_{2} \pi\left(e_{1}, \varepsilon_{2}\right) u\left(d_{1}\right)+v\left(\frac{y_{1}}{w_{2}}\right)\right]
\end{aligned}
$$

where $\lambda$ is the multiplier associated with the self-selection constraint.

The FOCs of this second-best problem are:

$$
\begin{aligned}
u^{\prime}\left(c_{1}\right)\left[1-\frac{\lambda}{n_{1}}\right]-\mu & =0 \\
u^{\prime}\left(c_{2}\right)\left[1+\frac{\lambda}{n_{2}}\right]-\mu & =0 \\
\pi\left(e_{1}, \varepsilon_{1}\right) u^{\prime}\left(d_{1}\right)-\frac{\alpha_{2} \pi\left(e_{1}, \varepsilon_{2}\right)}{n_{1}} \lambda u^{\prime}\left(d_{1}\right)-\mu \pi\left(e_{1}, \varepsilon_{1}\right) & =0 \\
\pi\left(e_{2}, \varepsilon_{2}\right) u^{\prime}\left(d_{2}\right)\left[1+\frac{\lambda \alpha_{2}}{n_{2}}\right]-\mu \pi\left(e_{2}, \varepsilon_{2}\right) & =0 \\
\pi_{e}\left(e_{1}, \varepsilon_{1}\right) u\left(d_{1}\right)-\left[1+\pi_{e}\left(e_{1}, \varepsilon_{1}\right) d_{1}\right] \mu & =\frac{\lambda}{n_{1}} \alpha_{2} \pi_{e}\left(e_{1}, \varepsilon_{2}\right) u\left(d_{1}\right) \\
\pi_{e}\left(e_{2}, \varepsilon_{2}\right) u\left(d_{2}\right)-\mu\left[1+\pi_{e}\left(e_{2}, \varepsilon_{2}\right) d_{2}\right] & =-\frac{\lambda}{n_{2}} \alpha_{2} \pi_{e}\left(e_{2}, \varepsilon_{2}\right) u\left(d_{2}\right) \\
v^{\prime}\left(\frac{y_{1}}{w_{1}}\right) \frac{1}{w_{1}}-\mu-\frac{\lambda}{n_{1}} v^{\prime}\left(\frac{y_{1}}{w_{2}}\right) \frac{1}{w_{2}} & =0 \\
v^{\prime}\left(\frac{y_{2}}{w_{2}}\right) \frac{1}{w_{2}}\left[1+\frac{\lambda}{n_{2}}\right]-\mu & =0
\end{aligned}
$$

\footnotetext{
${ }^{12}$ Replacing for first best allocations in individuals' utility functions, it is possible to
} prove that individual $i$ has interest in claiming to be of type $j$ whenever

$$
v\left(\frac{y_{j}}{w_{i}}\right)-v\left(\frac{y_{i}}{w_{i}}\right)+\alpha_{i}\left[\pi\left(e_{i}, \varepsilon_{i}\right)-\pi\left(e_{j}, \varepsilon_{i}\right)\right] u\left(d_{i}\right) \leq 0
$$


Rearranging these FOCs, we obtain the following marginal rates of substitution (MRS):

$$
\begin{aligned}
\frac{u^{\prime}\left(d_{2}\right)}{u^{\prime}\left(c_{2}\right)} & =1+\frac{\lambda}{n_{2} \mu}\left(1-\alpha_{2}\right) u^{\prime}\left(d_{2}\right) \\
\frac{u^{\prime}\left(d_{1}\right)}{u^{\prime}\left(c_{1}\right)} & =1+\frac{\lambda}{n_{1} \mu}\left[\frac{\alpha_{2} \pi\left(e_{1}, \varepsilon_{2}\right)}{\pi\left(e_{1}, \varepsilon_{1}\right)}-1\right] u^{\prime}\left(d_{1}\right) \\
\frac{\pi_{e}\left(e_{2}, \varepsilon_{2}\right) u\left(d_{2}\right)}{u^{\prime}\left(c_{2}\right)} & =\left[1+\pi_{e}\left(e_{2}, \varepsilon_{2}\right) d_{2}\right]+\frac{\lambda}{n_{2} \mu} \pi_{e}\left(e_{2}, \varepsilon_{2}\right) u\left(d_{2}\right)\left[1-\alpha_{2}\right](1) \\
\frac{\pi_{e}\left(e_{1}, \varepsilon_{1}\right) u\left(d_{1}\right)}{u^{\prime}\left(c_{1}\right)}= & {\left[1+\pi_{e}\left(e_{1}, \varepsilon_{1}\right) d_{1}\right] } \\
\frac{v^{\prime}\left(\frac{y_{2}}{w_{2}}\right)}{u^{\prime}\left(c_{2}\right)} & =w_{2} u\left(d_{1}\right)\left[\alpha_{2} \pi_{e}\left(e_{1}, \varepsilon_{2}\right)-\pi_{e}\left(e_{1}, \varepsilon_{1}\right)\right] \\
\frac{v^{\prime}\left(\frac{y_{1}}{w_{1}}\right)}{u^{\prime}\left(c_{1}\right)} & =w_{1}-\frac{\lambda}{n_{1} \mu}\left[v^{\prime}\left(\frac{y_{1}}{w_{2}}\right) \frac{w_{1}}{w_{2}}-v^{\prime}\left(\frac{y_{1}}{w_{1}}\right)\right]
\end{aligned}
$$

To interpret these expressions, assume first that $\alpha_{i}=1$. When $\lambda=0$, we are in the FB setting. The only discrepancy with the LF solution is in (17) and (18) and is due to the BP effect.

Let us reintroduce the self-selection constraint and keep $\alpha_{i}=1$. Equations (15) and (16) indicate that the Atkinson-Stiglitz (1976) property applies to saving by type 2 but not by type 1 . With complementarity of $\varepsilon$ and $e$, we have

$$
\frac{u^{\prime}\left(d_{1}\right)}{u^{\prime}\left(c_{1}\right)} \gtrless 1 \text { depending on } \varepsilon_{2} \gtrless \varepsilon_{1}
$$

The intuition behind that result goes as follows. If, for example, the mimicker has better genes $\left(\varepsilon_{2}>\varepsilon_{1}\right)$, he has higher chances to live longer than the mimicked individual and thus would like to save more for his retirement. It then makes sense to tax saving by the mimickee, which relaxes the incentive compatibility constraint. Again with $\alpha_{i}=1$, Equation (17) is not changed. As to (18), the factor of $\lambda$ is positive (negative) if $\varepsilon_{2}>(<) \varepsilon_{1}$. If $\varepsilon_{2}>\varepsilon_{1}$, both the incentive effect and the BP effect go in the same direction, so that it is optimal to tax health expenditures. Indeed, as the mimicker has better genes than the mimickee, he would like to invest more in his health, and thus taxing health spending by the mimickee relaxes the incentive constraint. In contrast, if $\varepsilon_{2}<\varepsilon_{1}$, the incentive constraint and the BP effect have countervailing effects, so that whether health expenditures should be subsidized or taxed 
is not clear. This depends on the magnitude of these two effects. Finally, concerning the choice of labor, there is no distortion for type 2 and there is the standard downward distortion for type 1.

As it appears, the myopia parameters appear in the above formulas, but they also appear in the LF optimal choices. This is why we now combine equations (15)-(20) and equations (12)-(14) to obtain the tax formulas.

\subsection{Tax formulas}

From equations (12)-(14) and (15)-(20), one can derive:

$$
\begin{aligned}
& \sigma_{1}=\alpha_{1}\left[\frac{1-\frac{\mu}{n_{1}}}{\left.1-\frac{\mu \alpha_{2} \pi\left(e_{1}, \varepsilon_{2}\right)}{n_{1} \pi\left(e_{1}, \varepsilon_{1}\right)}\right]-1}\right. \\
& \sigma_{2}=\alpha_{2}\left[\frac{1+\frac{\mu}{n_{2}}}{1+\frac{\mu \alpha_{2}}{n_{2}}}\right]-1 \\
& \theta_{1}=\alpha_{1}\left[1+\pi_{e}\left(e_{1}, \varepsilon_{1}\right) d_{1}\right]\left[\frac{1-\frac{\mu}{n_{1}}}{1-\frac{\mu \alpha_{2} \pi_{e}\left(e_{1}, \varepsilon_{2}\right)}{n_{1} \pi_{e}\left(e_{1}, \varepsilon_{1}\right)}}\right]-1 \\
& \theta_{2}=\alpha_{2}\left[1+\pi_{e}\left(e_{2}, \varepsilon_{2}\right) d_{2}\right]\left[\frac{1+\frac{\mu}{n_{2}}}{1+\frac{\mu \alpha_{2}}{n_{2}}}\right]-1 \\
& \tau_{1}=1-\frac{1-\frac{\mu}{n_{1}}}{1-\frac{\mu}{n_{1}} \frac{v^{\prime}\left(y_{1} / w_{2}\right)}{v^{\prime}\left(y_{1} / w_{1}\right)} \frac{w_{1}}{w_{2}}} \\
& \tau_{2}=0
\end{aligned}
$$

Note that, in those formulas, the myopia parameter appears as a factor of the MRS for health spending and saving, as well as in the MRS itself.

To interpret these tax formulas, we again start with the case without myopia (i.e. $\alpha_{i}=1 \forall i$ ). In the second-best, the tax-subsidy instruments are going to be used also to relax the incentive compatibility constraints, preventing type- 2 agents from mimicking type- 1 agents. Not surprisingly, this will depend on the distribution of the two characteristics. To see this, let us study the three alternative cases considered above, while noting that the no distortion at the top rule applies consistently to type- 2 agents. In other words, there is no distortion on the choice of labor and saving, and if there is any distortion on the choice of health care, it is due to the BP effect.

Let us recollect our three alternative cases:

A. negative correlation between genetics and productivity; 
B. positive correlation between genetics and productivity but the productivity gap dominates the genetic gap;

C. positive correlation between genetics and productivity but the productivity gap is dominated by the genetic gap.

In the alternative $\mathrm{A}$, type 2 dominates type 1 in productivity but not in genetics. The incentive compatibility (hereafter IC) effect thus leads to a tax on earnings and a subsidy on health spending and saving by type 1 . This is what shows column 2 of Table 2 . In the alternative B, type 2 dominates type 1 in both productivity and genetics. He is expected to work more, to spend more on health and on saving. To prevent him from mimicking type 1, one has to tax earnings, health care and saving of type 1 . In the alternative $\mathrm{C}$, type 2 has worse genes and a lower productivity than type 1. Reasoning as above, the IC effect implies a subsidy on earnings, on saving and on health expenditure by type 1 .

Naturally, as far as health expenditure is concerned, both the BP and the IC effects are to be combined, which gives a clear-cut tax in the second alternative and an ambiguous result in the first and the third ones.

Finally, let us consider the second-best with myopia. As in first-best, the presence of myopia implies a subsidy on both saving and health spending by the two types of individuals. In the case we had no tax or subsidy without myopia, we now have a subsidy. In the case we had a tax, we now have an ambiguous result. These various effects are presented on Table 2.

To interpret our aggregate results, let us focus on Case B, which seems to be the most plausible case. In that case, the second-best policy involves a tax on the earnings of agents with a low productivity and bad genes (and no tax on the earnings of agents with a high productivity and good genes), as well as a subsidy on the savings of agents with a high productivity and good genes. However, it is not obvious to see the sign of optimal taxation on health spending. As in the first-best, myopia (MO) recommends, for the two types of agents, a subsidization of longevity, while the BP effect recommends a taxation. But, in addition, the incentive compatibility (IC) supports a tax on the health spending of agents with low productivity and bad genes. As a result of those countervailing effects, it is not easy to see whether longevityenhancing spending should be taxed or subsidized. 
Table 2: Signs of taxes in the second-best

\begin{tabular}{|c|c|c|c|c|c|}
\hline second-best & & $\mathrm{BP}$ & $\mathrm{IC}$ & $\mathrm{MO}$ & Total effect \\
\hline \hline Case $\mathbf{A :}$ & $\sigma_{1}$ & 0 & - & - & - \\
\hline \hline$w_{2} \geqslant w_{1}$ & $\sigma_{2}$ & 0 & 0 & - & - \\
\hline and $\varepsilon_{1} \geq \varepsilon_{2}$ & $\theta_{1}$ & + & - & - & $?$ \\
\hline & $\theta_{2}$ & + & 0 & - & $?$ \\
\hline & $\tau_{1}$ & 0 & + & 0 & + \\
\hline & $\tau_{2}$ & 0 & 0 & 0 & 0 \\
\hline \hline Case B: & $\sigma_{1}$ & 0 & + & - & $?$ \\
\hline$w_{2} \geqslant w_{1}$ & $\sigma_{2}$ & 0 & 0 & - & - \\
\hline and $\varepsilon_{1}<\varepsilon_{2}$ & $\theta_{1}$ & + & + & - & $?$ \\
\hline & $\theta_{2}$ & + & 0 & - & $?$ \\
\hline & $\tau_{1}$ & 0 & + & 0 & + \\
\hline & $\tau_{2}$ & 0 & 0 & 0 & 0 \\
\hline \hline Case C: & $\sigma_{1}$ & 0 & - & - & - \\
\hline$w_{2}<w_{1}$ & $\sigma_{2}$ & 0 & 0 & - & - \\
\hline and $\varepsilon_{1}>\varepsilon_{2}$ & $\theta_{1}$ & + & - & - & $?$ \\
\hline & $\theta_{2}$ & + & 0 & - & $?$ \\
\hline & $\tau_{1}$ & 0 & - & 0 & - \\
\hline & $\tau_{2}$ & 0 & 0 & 0 & 0 \\
\hline
\end{tabular}

Given that the signs of several instruments are ambiguous, it is necessary, to have more precise conclusions, to complement that qualitative analysis by some numerical simulations under particular functional forms for individual utility functions and for survival functions. That task is carried out in the Appendix of the paper.

\section{Discussions}

Let us come back to the three assumptions that play a key role in our model. The first crucial assumption concerns the distributions of $w$ and $\varepsilon$ in the population, the second assumption concerns the degree of substitutability between $\varepsilon$ and $e$ in the production of longevity, and the third assumption consists of the social criterion used (classical utilitarianism).

\subsection{The productivity / genes correlation}

Concerning the first assumption, there is little doubt that, in the real world, there exists a large number of types regarding our two characteristics. Agents 
exhibiting a high productivity do not necessarily benefit from good longevity genes, and agents with bad longevity genes may nonetheless turn out to be highly productive. Hence, under two sources of heterogeneity, we should ideally consider four - instead of two - types of agents (leaving myopia aside).

Nonetheless, for reason of analytical treatment, we limited ourselves here to two types of agents, and, under this restriction, we argued that the most realistic case is, at their glance, the existence of a positive correlation between the characteristics $\varepsilon$ and $w$ (i.e. ruling out Case A). Further, to the extent we want type- 2 agents to mimic type- 1 agents, the most realistic case is the one with positive correlation between $\varepsilon$ and $w$ and the productivity gap larger than the genetic gap (with complementarity), that is, Case B.

While those restrictions - and the resulting emphasis on Case B - facilitate the exposition of the problem, it should be stressed here that assumptions on the relationship between productivity and longevity genes are not straightforward to make. The reason why those assumptions are somewhat fragile lies mainly in the difficulty to identify what we call the 'longevity genes'. The genetic background is so large that it is not obvious to see what 'longevity genes' consist of, and the precise definition of those 'longevity genes' may affect the plausibility of the different cases. One cannot rule out a priori that some longevity genes are positively correlated with productivity, while others are negatively correlated with longevity, so that assumptions at the aggregate level should be made with caution.

Thus, even though Case B seems, at first sight, to be the most plausible one, other cases should not be ignored, and this is why we studied also the other cases for completeness.

\subsection{The production of longevity}

Regarding the degree of substitutability between $e$ and $\varepsilon$, we believe that the assumption of complementarity is the most realistic one. This means that having good genes implies that for the same amount of effort, one increases his survival probability more than someone with bad genes.

Having stressed this, it should be underlined that substitutability, although less plausible, is far from impossible. In order to illustrate the issue at hand, let us consider the following example. Suppose we have two individuals endowed with a different metabolism and striving to achieve an ideal weight. For the one with a favorable metabolism, just a little effort will allow him to reach his ideal weight. However, for the other person, even with enormous efforts, it will be mission impossible. In the light of that example, the case of complementarity does not seem as strong as it may appear at first 
sight. ${ }^{13}$ Given that the empirical testing of those two assumptions can hardly be made (because of the reason mentioned above regarding the identification of 'longevity genes'), it makes sense to explore the policy consequences of departing from complementarity of $\varepsilon$ and $e$.

To see the implication of adopting the assumption of substitutability, we contrast on Table 3 the tax rates under substitutability and complementarity for the case $\mathrm{B}$ (i.e. positive correlation between $w$ and $e$ and the productivity gap dominating the genetic gap).

Table 3: Complementarity versus substitutability

\begin{tabular}{|c|c|c|c|c|c|}
\hline Case B: & & $\mathrm{BP}$ & $\mathrm{IC}\left(\alpha_{i}=1\right)$ & $\mathrm{MO}$ & Total effect \\
\hline positive correlation $\left(w_{i}, \varepsilon_{i}\right)$ & & & & & \\
\hline \hline Complementarity & $\sigma_{1}$ & 0 & + & - & $?$ \\
\hline & $\sigma_{2}$ & 0 & 0 & - & - \\
\hline & $\theta_{1}$ & + & + & - & $?$ \\
\hline & $\theta_{2}$ & + & 0 & - & $?$ \\
\hline & $\tau_{1}$ & 0 & + & 0 & + \\
\hline & $\tau_{2}$ & 0 & 0 & 0 & 0 \\
\hline \hline & $\sigma_{1}$ & 0 & + & - & $?$ \\
\hline & $\sigma_{2}$ & 0 & 0 & - & - \\
\hline & $\theta_{1}$ & + & $?$ & - & $?$ \\
\hline & $\theta_{2}$ & + & 0 & - & $?$ \\
\hline & $\tau_{1}$ & 0 & + & 0 & + \\
\hline & $\tau_{2}$ & 0 & 0 & 0 & 0 \\
\hline
\end{tabular}

As one can see from Table 3, going from complementarity to substitutability only influences the IC effect for $\theta_{1}$, as it only affects the ratio $\pi_{e}\left(e_{1}, \varepsilon_{2}\right) / \pi_{e}\left(e_{1}, \varepsilon_{1}\right)$. Thus we now have an ambiguous sign for $\theta_{1}$, whereas it was positive with complementarity. ${ }^{14}$

\subsection{Classical utilitarianism}

Finally, there is a key assumption that we have made up to now, and which has some bearing on the result: it is the classical utilitarian objective function. When combined with the standard additive lifetime welfare assumption, the classical utilitarian criterion amounts to impose a redistribution

\footnotetext{
${ }^{13}$ Actually, that example supports some substitutability of genes and effort in the production of longevity, for which a general expression is given by the following CES function: $\pi(e, \varepsilon)=\left(e^{v}+\varepsilon^{v}\right)^{\chi / v}$, where $v \leqslant 1$ and $\chi<1$.

${ }^{14}$ See the Appendix for a numerical comparison of the complementarity and substitutability cases.
} 
from short-lived to long-lived individuals. ${ }^{15}$ Such a redistribution can be questioned, as it is not obvious to see why an individual should be penalized because he lives a shorter life than other individuals. Intuitively, one would prefer, on the contrary, to see short-lived agents 'compensated' for their short life, for which they are not responsible. Classical utilitarianism does not allow for such a compensation.

In order to avoid the counter-intuitive redistributive bias in favor of longlived agents, there is no other solution than to depart from the standard utilitarian optimization problem described above. This can be done in several manners. One intuitive solution is to modify the weighting of individual utilities. ${ }^{16}$ Whereas classical utilitarianism weights equally the utility of all agents, and of all life-periods, one may depart from such a weighting of utilities in two ways. One can put a higher weight on the lifetime utility of the short-lived individuals, or, alternatively, one can put a higher weight on the second-period utility of the short-lived individuals.

For the sake of illustration, let us put a higher weight on the secondperiod utility of the short-lived individuals. If we take our benchmark case $\mathrm{B}$ and focus on the first-best, the Lagrange expression can be rewritten as:

$$
\begin{aligned}
& \sum n_{i}\left[u\left(c_{i}\right)+\beta_{i} \pi\left(e_{i}, \varepsilon_{i}\right) u\left(d_{i}\right)-v\left(l_{i}\right)\right. \\
& \left.-\lambda\left(c_{i}+e_{i}+\pi\left(e_{i}, \varepsilon_{i}\right) d_{i}-w_{i} l_{i}\right)\right]
\end{aligned}
$$

where $\beta_{2}=1$ and $\beta_{1}>1$.

As before, we have $c_{1}=c_{2}$ and $l_{2}>l_{1}$. But now we have: $d_{1}>d_{2}$. Type-1 agents will consume more during his second period than type- 2 agents. If we move to the second-best, those weights make the mimicking of type- 1 by type-2 individuals more attractive than without the modified weights. Note, however, that this does not change the self-selection constraint as long as the mimicked individuals are also those having a low longevity.

\section{Conclusions}

This paper studied the optimal non-linear taxation policy in a two-period economy where the probability of survival to the second period depends on genetic background and on health spending. Agents were assumed to be

\footnotetext{
${ }^{15}$ For a criticism of that redistribution, see Bommier et al (2007b).

${ }^{16}$ Another solution, not explored in this paper, is to keep the standard utilitarian criterion, but do as if all agents have the same genetic background (even though it is not the case). Such a paternalistic approach amounts to fix $\varepsilon_{i}=\bar{\varepsilon}$ for all agents in the objective function, while keeping group-specific $\varepsilon_{i}$ in incentive compatibility constraints.
} 
heterogeneous on three dimensions: longevity genes, earnings capacity and the degree of myopia. The social planner was assumed to be of the standard, classical utilitarian type, that is, maximizing the sum of individual utilities, but using the true and not the perceived survival probability.

In the first-best, i.e. when the social planner observes individual characteristics, the decentralization of the optimum calls for Pigouvian actions that consist of a subsidy to foster health spending and saving in case of myopia, and of a tax to discourage health spending to the extent that individuals do not see the impact of increased longevity on the returns of annuities.

In the second-best, beyond these Pigouvian actions, the non-observability of productivity and genetic endowment implies a self-selection constraint leading to a tax or a subsidy on saving, health spending and earnings for the mimicked agents, depending on the relative values of non observable characteristics. Whether health and saving ought to be subsidized or taxed depends on the combined effects of myopia, self-selection and free-riding on the annuity returns.

Take, for instance, the benchmark case of positive correlation with the productivity gap dominating the genetic gap, and of complementarity between health spending and genetic endowment. In the absence of myopia, we have a tax on earnings, health spending and saving for agents with low productivity and genes, and a tax on health spending for agents with high productivity and genes. Note that taxing saving and also health care violates the Atkinson-Stiglitz (1976) theorem, but such a violation follows from the existence of two characteristics (see Cremer et al., 2004). The tax on health spending can also appear quite surprising. However, we have to remember that redistribution is here implemented by the optimal tax on earnings, and that the type of health we have here in mind is mainly consumed by the mimicker (i.e. agents with good genes). Moreover, once myopia is introduced, there is a countervailling argument for subsidizing health care.

Finally, it cannot be overemphasized here that the present study, by relying mainly on classical utilitarianism, suffers from the limitations of that ethical framework in the context of varying longevity. ${ }^{17}$ In particular, the utilitarian bias in favor of agents with good genes is quite counter-intuitive. Intuitively, one would prefer agents with a bad genetic background to be compensated for this, on the grounds that these are not responsible for having bad longevity genes. But utilitarianism, by relying on consequentialism, can hardly do justice to such responsibility-based intuitions. In order to discuss the sensitivity of our results to the utilitarian postulate, we considered an alternative social welfare function in which we abandon the utilitarian bias

\footnotetext{
${ }^{17}$ See Broome (2004) on the problems raised by longevity for teleological ethical systems.
} 
in favor of long-lived individuals. As we showed, giving more social weight to the short-lived individuals increases redistribution in their favor, but does not change the self-selection constraint as long as the mimicked agents are also those having a low longevity.

However, given the singularity, from an ethical point of view, of the longevity dimension, that slight departure from the Benthamite social welfare function invites several other departures, allowing us to explore in more depth the sensitivity of policy recommendations to the postulated ethical framework. In the light of the well-known difficulties to accommodate utilitarianism with intuitions about responsibility and compensation, there can be no doubt that much work remains to be done in the future.

\section{References}

[1] Atkinson, A. and J. Stiglitz (1976), The design of tax structure. Direct versus indirect taxation, Journal of Public Economics, 6, 55-75.

[2] Banks, J. and P. Diamond (2008), The base for direct taxation, in Mirrlees Review, unpublished.

[3] Becker, G. and Philippson (1998), Old age longevity and mortality contingent claims, Journal of Political Economy, 106, 551-573.

[4] Becker, G., T. Philipson and Soares R., (2005), The quantity and the quality of life and the evolution of world inequality, The American Economic Review, 95(1), pp. 277-291.

[5] Bommier, A. (2006), Uncertain lifetime and intertemporal choice, International Economic Review, 47, 1223-1346.

[6] Bommier, A., M-L. Leroux and J-M. Lozachmeur, (2007a), Social Security and differential mortality. Working Paper.

[7] Bommier, A., M-L. Leroux and J-M. Lozachmeur, (2007b), Uncertain Lifetime, Redistribution and Nonlinear Pricing of Annuities. Working Paper.

[8] Broome, J. (2004), Weighing Lives. Oxford University Press.

[9] Cremer, H., J.M. Lozachmeur and P. Pestieau (2008), Collective annuities and redistribution, unpublished 
[10] Cremer, H., P. Pestieau and J. Ch. Rochet (2004), Direct versus indirect taxation: the design of the tax structure revisited, International Economic Review, 42(3), 781-799, 2001.

[11] Eeckhoudt, L and P. Pestieau, (2008), Fear of ruin and longevity enhancing investment, Economics Letters, forthcoming

[12] Jouvet, P.A., Pestieau, P., Ponthiere, G., (2007), Longevity and environmental quality in an OLG model, CORE Discussion Paper 69.

[13] Leroux, M-L. (2008), Endogenous differential mortality, non monitored effort and optimal non linear taxation, CORE Discussion Paper 29.

[14] Leroux, M-L., Ponthiere, G. (2008), Optimal tax policy and expected longevity. A mean and variance approach, CORE Discussion Paper 39.

[15] Leroux, M-L., P. Pestieau and G. Ponthiere (2008), Optimal linear taxation under endogenous longevity, CORE Discussion Paper 51.

[16] Murphy, K.M, Topel R.H., (2006), The value of health and longevity. Journal of Political Economy, 114(5), pp. 871-904.

[17] Pestieau, P., Ponthiere, G., \& Sato, M (2008), Longevity, health spending and PAYG pensions, FinanzArchiv, 64(1), 1-18.

[18] Zhang, J., Zhang, J. \& Leung, M.C., (2006), Health investment, saving, and public policy, Canadian Journal of Economics, 39 (1), pp. 68-93. 


\section{Appendix: a numerical example}

We here present some numerical examples that illustrate our cases A and B under the alternative assumptions of complementarity and substitutability between genes and health spending. We adopt the following specifications for the various components of our model. Per period utility of consumption and desutility of labour are expressed as follows:

$$
\begin{aligned}
& u(c)=\frac{c^{1-\sigma}}{1-\sigma} \\
& v(l)=\frac{l^{2}}{2}
\end{aligned}
$$

where $\sigma$ is the coefficient of relative risk aversion; it is set equal to 0.8 . We also use the following forms for the survival probabilities in the cases of complementarity $(c)$ and substitutability $(s)$ between health spending and genes:

$$
\begin{aligned}
\pi(e, \varepsilon)^{c} & =\frac{\varepsilon}{1+\varepsilon} \frac{e}{1+e} \\
\pi(e, \varepsilon)^{s} & =\frac{(e+\varepsilon)^{1 / 2}}{1+(e+\varepsilon)^{1 / 2}}
\end{aligned}
$$

Note that both formulations ensure that the survival probability is always lower or equal to one. As in our theoretical model, we assume two groups of individuals with productivites $w_{1}=1<w_{2}=10$. As to the genetic endowment, we assume $\varepsilon_{1}=1$ and let $\varepsilon_{2}$ vary. We finally assume $\alpha=0.9$, so that individuals have an identical and low degree of myopia.

The following table presents the levels of taxes on savings $\left(\sigma_{1}\right)$, health $\left(\theta_{1}\right)$ and labour $\left(\tau_{1}\right)$ under the assumption of complementarity between genes and health expenditure for the mimickee, under asymmetric information.

\begin{tabular}{|c||c|c|c|c|c|c|c|c|c|}
\hline$\varepsilon_{2}$ & 0.2 & 0.5 & 0.8 & 1 & 1.2 & 1.5 & 1.8 & 2 & 3 \\
\hline \hline$\sigma_{1}$ & -0.27 & -0.21 & -0.16 & -0.13 & -0.11 & -0.07 & -0.05 & -0.03 & 0.02 \\
$\theta_{1}$ & -0.09 & -0.01 & 0.05 & 0.09 & 0.12 & 0.16 & 0.19 & 0.21 & 0.28 \\
$\tau_{1}$ & 0.25 & 0.25 & 0.25 & 0.25 & 0.25 & 0.25 & 0.25 & 0.26 & 0.26 \\
\hline
\end{tabular}

Note that when $\varepsilon_{2} \in[0,1[$, productivity and genes are negatively correlated, so that we are in our theoretical case A. On the contrary, for any $\varepsilon_{2} \geq 1$, it corresponds to case B. Irrespectively of cases A or B, we have a tax on earnings. As $\varepsilon_{2}$ increases, we go from a subsidy to a tax on health. We have a subsidy on saving except when the genetic gap becomes large enough 
making it worthwhile to tax saving. These results are consistent with our theoretical findings (see Table 2).

Our second table presents the results under the assumption of substitutability between genes and health spending, only in our benchmarck case $\mathrm{B}$ of positive correlation between genes and productivity with a productivity gap dominating the genetic gap.

\begin{tabular}{|c||c|c|c|c|c|c|}
\hline$\varepsilon_{2}$ & 1 & 1.2 & 1.5 & 1.8 & 2 & 3 \\
\hline \hline tax on savings $\left(\sigma_{1}\right)$ & -0.13 & -0.13 & -0.12 & -0.12 & -0.11 & -0.10 \\
tax on health $\left(\theta_{1}\right)$ & 0.09 & 0.06 & 0.02 & 0.00 & -0.01 & -0.06 \\
tax on labour $\left(\tau_{1}\right)$ & 0.26 & 0.26 & 0.26 & 0.26 & 0.26 & 0.26 \\
\hline
\end{tabular}

As expected, the assumption of substitutability does not change the sign of $\tau_{1}$; it is still optimal to tax earnings. On the contrary, we now find that health should be subsidized for $\varepsilon_{2}>1.8$. As to saving, we have a subsidy for all the values of $\varepsilon_{2}$, whereas with complementarity, we have a tax for a large genetic gap. This is consistent with the theory. With substitutability a higher genetic endowment calls for less and not more health spending. As one can see the subsidy decreases with $\varepsilon_{2}$.

Finally, we would like to see how the results change when we assign different social weights to individuals with different genes. We consider case $\mathrm{B}$ and we want the weight to neutralize genetic differences. This can be done by writing the lifetime utility of our two types as follows:

$$
U\left(c_{i}, d_{i}, l_{i}\right)=u\left(c_{i}\right)+\beta_{i} \pi\left(e_{i}, \varepsilon_{i}\right) u\left(d_{i}\right)-v\left(l_{i}\right)
$$

with $\beta_{i}=\left(1+\varepsilon_{i}\right) / \varepsilon_{i}$. With such a weighting, we obtain the following tax values:

\begin{tabular}{|c||c|c|c|c|c|c|}
\hline$\varepsilon_{2}$ & 1 & 1.2 & 1.5 & 1.8 & 2 & 3 \\
\hline \hline tax on savings $\left(\sigma_{1}\right)$ & -0.14 & -0.11 & -0.06 & -0.03 & -0.004 & 0.08 \\
tax on health $\left(\theta_{1}\right)$ & 0.07 & 0.12 & 0.17 & 0.22 & 0.24 & 0.35 \\
tax on labour $\left(\tau_{1}\right)$ & 0.33 & 0.33 & 0.32 & 0.32 & 0.32 & 0.32 \\
\hline
\end{tabular}

Comparing these values with those obtained without weight we observe that the tax on both earnings and health is higher and the subsidy on saving is lower. This is due to the fact that with our weights, redistribution from type 2 to type 1 is more important. To achieve it under asymmetric information we need higher taxes or lower subsidies to satisfy the self selection constraint. 


\section{Recent titles \\ CORE Discussion Papers}

2008/20. Helmuth CREMER, Philippe DE DONDER, Dario MALDONADO and Pierre PESTIEAU. Forced saving, redistribution and nonlinear social security schemes.

2008/21. Philippe CHEVALIER and Jean-Christophe VAN DEN SCHRIECK. Approximating multiple class queueing models with loss models.

2008/22. Pierre PESTIEAU and Uri M. POSSEN. Interaction of defined benefit pension plans and social security.

2008/23. Marco MARINUCCI. Optimal ownership in joint ventures with contributions of asymmetric partners.

2008/24. Raouf BOUCEKKINE, Natali HRITONENKO and Yuri YATSENKO. Optimal firm behavior under environmental constraints.

2008/25. Ana MAULEON, Vincent VANNETELBOSCH and Cecilia VERGARI. Market integration in network industries.

2008/26. Leonidas C. KOUTSOUGERAS and Nicholas ZIROS. Decentralization of the core through Nash equilibrium.

2008/27. Jean J. GABSZEWICZ, Didier LAUSSEL and Ornella TAROLA. To acquire, or to compete? An entry dilemma.

2008/28. Jean-Sébastien TRANCREZ, Philippe CHEVALIER and Pierre SEMAL. Probability masses fitting in the analysis of manufacturing flow lines.

2008/29. Marie-Louise LEROUX. Endogenous differential mortality, non monitored effort and optimal non linear taxation.

2008/30. Santanu S. DEY and Laurence A. WOLSEY. Two row mixed integer cuts via lifting.

2008/31. Helmuth CREMER, Philippe DE DONDER, Dario MALDONADO and Pierre PESTIEAU. Taxing sin goods and subsidizing health care.

2008/32. Jean J. GABSZEWICZ, Didier LAUSSEL and Nathalie SONNAC. The TV news scheduling game when the newscaster's face matters.

2008/33. Didier LAUSSEL and Joana RESENDE. Does the absence of competition in the market foster competition for the market? A dynamic approach to aftermarkets.

2008/34. Vincent D. BLONDEL and Yurii NESTEROV. Polynomial-time computation of the joint spectral radius for some sets of nonnegative matrices.

2008/35. David DE LA CROIX and Clara DELAVALLADE. Democracy, rule of law, corruption incentives and growth.

2008/36. Jean J. GABSZEWICZ and Joana RESENDE. Uncertain quality, product variety and price competition. 2008/37. Gregor ZOETTL. On investment decisions in liberalized electricity markets: the impact of price caps at the spot market.

2008/38. Helmuth CREMER, Philippe DE DONDER, Dario MALDONADO and Pierre PESTIEAU. Habit formation and labor supply.

2008/39. Marie-Louise LEROUX and Grégory PONTHIERE. Optimal tax policy and expected longevity: a mean and variance approach.

2008/40. Kristian BEHRENS and Pierre M. PICARD. Transportation, freight rates, and economic geography.

2008/41. Gregor ZOETTL. Investment decisions in liberalized electricity markets: A framework of peak load pricing with strategic firms.

2008/42. Raouf BOUCEKKINE, Rodolphe DESBORDES and Hélène LATZER. How do epidemics induce behavioral changes?

2008/43. David DE LA CROIX and Marie VANDER DONCKT. Would empowering women initiate the demographic transition in least-developed countries?

2008/44. Geoffrey CARUSO, Dominique PEETERS, Jean CAVAILHES and Mark ROUNSEVELL. Space-time patterns of urban sprawl, a 1D cellular automata and microeconomic approach.

2008/45. Taoufik BOUEZMARNI, Jeroen V.K. ROMBOUTS and Abderrahim TAAMOUTI. Asymptotic properties of the Bernstein density copula for dependent data. 


\section{Recent titles}

\section{CORE Discussion Papers - continued}

2008/46. Joe THARAKAN and Jean-Philippe TROPEANO. On the impact of labor market matching on regional disparities.

2008/47. Shin-Huei WANG and Cheng HSIAO. An easy test for two stationary long processes being uncorrelated via AR approximations.

2008/48. David DE LA CROIX. Adult longevity and economic take-off: from Malthus to Ben-Porath.

2008/49. David DE LA CROIX and Gregory PONTHIERE. On the Golden Rule of capital accumulation under endogenous longevity.

2008/50. Jean J. GABSZEWICZ and Skerdilajda ZANAJ. Successive oligopolies and decreasing returns.

2008/51. Marie-Louise LEROUX, Pierre PESTIEAU and Grégory PONTHIERE. Optimal linear taxation under endogenous longevity.

2008/52. Yuri YATSENKO, Raouf BOUCEKKINE and Natali HRITONENKO. Estimating the dynamics of R\&D-based growth models.

2008/53. Roland Iwan LUTTENS and Marie-Anne VALFORT. Voting for redistribution under desertsensitive altruism.

2008/54. Sergei PEKARSKI. Budget deficits and inflation feedback.

2008/55. Raouf BOUCEKKINE, Jacek B. KRAWCZYK and Thomas VALLEE. Towards an understanding of tradeoffs between regional wealth, tightness of a common environmental constraint and the sharing rules.

2008/56. Santanu S. DEY. A note on the split rank of intersection cuts.

2008/57. Yu. NESTEROV. Primal-dual interior-point methods with asymmetric barriers.

2008/58. Marie-Louise LEROUX, Pierre PESTIEAU and Gregory PONTHIERE. Should we subsidize longevity?

\section{Books}

Y. POCHET and L. WOLSEY (eds.) (2006), Production planning by mixed integer programming. New York, Springer-Verlag.

P. PESTIEAU (ed.) (2006), The welfare state in the European Union: economic and social perspectives. Oxford, Oxford University Press.

H. TULKENS (ed.) (2006), Public goods, environmental externalities and fiscal competition. New York, Springer-Verlag.

V. GINSBURGH and D. THROSBY (eds.) (2006), Handbook of the economics of art and culture. Amsterdam, Elsevier.

J. GABSZEWICZ (ed.) (2006), La différenciation des produits. Paris, La découverte.

L. BAUWENS, W. POHLMEIER and D. VEREDAS (eds.) (2008), High frequency financial econometrics: recent developments. Heidelberg, Physica-Verlag.

P. VAN HENTENRYCKE and L. WOLSEY (eds.) (2007), Integration of AI and OR techniques in constraint programming for combinatorial optimization problems. Berlin, Springer.

\section{CORE Lecture Series}

C. GOURIÉROUX and A. MONFORT (1995), Simulation Based Econometric Methods.

A. RUBINSTEIN (1996), Lectures on Modeling Bounded Rationality.

J. RENEGAR (1999), A Mathematical View of Interior-Point Methods in Convex Optimization.

B.D. BERNHEIM and M.D. WHINSTON (1999), Anticompetitive Exclusion and Foreclosure Through Vertical Agreements.

D. BIENSTOCK (2001), Potential function methods for approximately solving linear programming problems: theory and practice.

R. AMIR (2002), Supermodularity and complementarity in economics.

R. WEISMANTEL (2006), Lectures on mixed nonlinear programming. 